\title{
Accuracy of Four Electronic Apex Locators During Root Canal Length Determination
}

\author{
Precisión de Cuatro Localizadores de Ápice en \\ la Determinación de la Longitud de Trabajo
}

\author{
Pablo Betancourt'; Daniela Matus²; Javiera Muñoz²; Pablo Navarro' \& Scarlette Hernández ${ }^{3}$
}

BETANCOURT, P.; MATUS, D.; MUÑOZ, J.; NAVARRO, P. \& HERNÁNDEZ, S. Accuracy of four electronic apex locators during root canal length determination. Int. J. Odontostomat., 13(3):287-291, 2019.

ABSTRACT: The apical limit of tooth roots for instrumentation and obturation is a controversial subject due to the high morphological complexity presented by the apical zone of the root. The development of electronic apex locators (EALs) has made working length (WL) determination more predictable, producing more accurate results; however, the interpretation mechanisms of different devices may affect measurements taken under different clinical conditions. One hundred premolars were used to compare the effectiveness of Propex II, Raypex 6, Propex Pixi and Root ZX II in locating the apical foramen (AF). No statistically significant differences were observed when the accuracy of measurement was compared between the different groups of EALs, however Root ZX II and Raypex 6 presented the best overall performance.

KEY WORDS: tooth root, anatomy, endodontics, electronic apex locator.

\section{INTRODUCTION}

The success of endodontic treatment depends on the correct mechanical enlargement, disinfection and sealing of the root canal system (D'Assunção et al., 2007). These objetives can only be achieved with accurate determination of the working length (WL) (Ding et al., 2010). The WL is defined as "the distance from a coronal reference point on the tooth to the point where canal preparation and obturation should terminate" (American Association of Endodontists, 2003). An error in determining the WL may lead to insufficient debridement of the root canal, delaying healing and increasing postoperative pain (DuranSindreu et al., 2012).

The apical limit of tooth roots for instrumentation and obturation is a controversial subject due to the high morphological complexity presented by the apical zone of the root. Various authors have suggested that determining the exact location of the apical constriction is extremely complex because it is not present in all teeth (Martínez-Lozano et al., 2001; Lee et al., 2002; de Vasconcelos et al., 2014). As a result the apical foramen (AF) has been described as the most stable anatomical reference point for taking the measurement (Somma et al., 2012; Oliveira et al., 2017).

The development of electronic apex locators (EALs) has made WL determination more predictable, producing more accurate results (Haffner et al., 2005; Altunbas, et al., 2014). Their action mechanism is based on a resistance in the electrical conductivity between the tissues which surround the root apex and the interior of the root canal (Custer, 1918). One of the main advantages is that it reduces the patient's exposure to ionising radiation by reducing the number of radiographies (Tampelini et al., 2017).

A large number of different models of EALs have been developed in recent years, however, although they work on the same principle, they operate with different mechanisms. Some use the impedance quotient principle, such as Root ZX II (J Morita, Tokyo, Japan) (Altunbas, et al., 2014). The Propex II (Dentsply

\footnotetext{
${ }^{1}$ Research Centre for Dental Sciences (CICO), Endodontic Laboratory, Dental School, Universidad de La Frontera, Temuco, Chile.

${ }^{2}$ Dental School, Universidad de La Frontera, Temuco, Chile.

${ }^{3}$ Faculty of Medicine, Austral University of Chile, Valdivia, Chile.
} 
Maillefer, Ballaigues, Switzerland) (Marroquín et al., 2014), the Raypex 6 (VDW GmbH, Munich, Germany) (Marigo et al., 2016) and the Propex Pixi (Dentsply Maillefer) (Üstün et al., 2016) use the square root of the impedances in 2 frequencies. These impedance interpretation mechanisms can affect measurements taken under different clinical conditions (Vaconcelos et al., 2015).

Considering the different models of EALs available in the market and the importance of measuring the WL correctly for successful endodontic treatment, the purpose of the present study was to compare ex vivo the effectiveness of Propex II, Raypex 6, Propex Pixi and Root ZX II in locating the AF.

\section{MATERIAL AND METHOD}

One hundred single-rooted mandibular premolars, from both sides, extracted for periodontal or orthodontic indication were selected from the Universidad de La Frontera, Temuco, Chile. Teeth with caries, fracture or root resorption were excluded. Each tooth was cleaned with ultrasound points (Satelec® Zirconium Endo Pro Ultra, Dentsply Maillefer, Ballaigues, Switzerland) to eliminate calculus and periodontal tissue. The teeth were then immersed in $2.5 \%$ sodium hypochlorite $(\mathrm{NaOCl})$ for 2 hours and stored in sterile saline solution at $0.9 \%$ until use. The teeth were decrowned at the cemento-enamel junction with a diamond disc and the coronary third was prepared using an SX file (Denstply, Maillefer, Ballaigues, Switzerland). The permeability of the apical foramen was verified with a K\#10 file (Dentsply, Maillefer, Ballaigues, Switzerland) to discount any obstruction of the canal.

The real length $(R L)$ was determined by stereoscopic microscope (Stemi DV4, Carl Zeiss, Göttingen, Germany) at 20X. A K\#15 file (Dentsply, Maillefer, Ballaigues, Switzerland) was introduced into the root canal until it emerged from the AF, then withdrawn until the point of the instrument was tangential to the AF. The distance was measured between the rubber stop and the point of the file, adjusting the measurement to the nearest tenth of a millimetre if necessary.

To determine the location of the AF electronically, the teeth were assigned at random to four groups of 25 teeth each: (I) Propex II, (II) Raypex 6, (III) Propex
Pixi, (IV) Root ZX II. The radicular apex portions were immersed in recently prepared alginate to simulate periodontal ligament; the labial clip was also immersed in the alginate to complete the circuit. The canals were irrigated with $2.5 \% \mathrm{NaOCl}$ and sterile cotton rolls were used to eliminate the excess irrigant. To take the electronic measurements, a K\#15 file (Denstply, Maillefer, Ballaigues, Switzerland) was introduced into the canal with Roane movements. The file was advanced with gentle apical pressure until Propex II and Propex Pixi indicated 0.0, Raypex 6 the last red line and Root ZX II the last green line. The measures were considered valid if the EAL remained stable for at least 5 seconds. Then the silicon stop was adjusted to the reference and the file was removed. The distance between the rubber stop and the point of the file was measured with an endodontic ruler, adjusting the measurement to the nearest tenth of a millimetre if necessary. The measurements were taken during a period of two hours by a single operator, who was an endodontic specialist and had previously been calibrated in the use of different apical locators.

To determine the effectiveness of the different EALs in determining the position of the AF, the difference between the $R L$ and the electronic length (EL) of each tooth was calculated. Positive values indicated that the apical foramen had been passed, whereas negative values indicated that the AF had not been reached and a value of 0 indicated coinciding measurements. The measurement lengths were assigned as follows: 1 : $<-1 \mathrm{~mm} ; 2:-0.99$ to $-0.51 \mathrm{~mm}$; 3: -0.50 to $-0.01 \mathrm{~mm} ; 4: 0$ to $0.49 \mathrm{~mm} ; 5: 0.50$ to 0.99 $\mathrm{mm} ; 6$ : $>1 \mathrm{~mm}$.

The data collected were recorded in a Microsoft Office Excel spreadsheet. Data were analysed using the SPSS Statistics programme (version 23.0, IBM), with descriptive analysis of the data determining the mean and standard deviation. The Shapiro-Wilk normality test, Kruskal-Wallis test and Chi-squared test of categoric variables were applied with confidence intervals of $95 \%$ for the population mean. A value of $p$ $<0.05$ was selected as the threshold of statistical significance.

\section{RESULTS}

The Kruskal-Wallis test showed no statistically significant differences in the comparison of the accuracy of measurements between the different 
groups of EALs (Propex Pixi, Root ZX II, Propex II and Raypex 6), $p=0.830$. The Root $Z X ~ I I$ had an accuracy of $92.00 \%$ at $\pm 0.5 \mathrm{~mm}$ and $97.05 \%$ at $\pm 1 \mathrm{~mm}$, while the Raypex 6 had an accuracy of $92.00 \%$ at both \pm
$0.5 \mathrm{~mm}$ and $\pm 1 \mathrm{~mm}$. They were followed by Propex II with $80 \%$ accuracy at \pm 0.5 and $88 \%$ at $\pm 1.0 \mathrm{~mm}$. The last was Pixi with accuracy of $76 \%$ at \pm 0.5 and $85 \%$ at $\pm 1.0 \mathrm{~mm}$ (Table I). The mean distances from the file point to the AF are shown in Table II.

Table I. Frequency of distance $(\mathrm{mm})$ between the file and the apical foramen (AF).

\begin{tabular}{lccccc}
\hline CATEGORY & Pixi & Root ZX II & Propex II & Raypex 6 & Total \\
\hline$<-1$ & $2(8 \%)$ & $1(4 \%)$ & $1(4 \%)$ & $1(4 \%)$ & $5(5 \%)$ \\
-0.99 to -0.51 & $2(8 \%)$ & $1(4 \%)$ & $1(4 \%)$ & $0(0 \%)$ & $4(4 \%)$ \\
-0.50 to -0.01 & $10(40 \%)$ & $12(48 \%)$ & $11(44 \%)$ & $12(48 \%)$ & $45(45 \%)$ \\
0 to 0.49 & $9(36 \%)$ & $11(44 \%)$ & $9(36 \%)$ & $11(44 \%)$ & $40(40 \%)$ \\
0.5 to 0.99 & $0(0 \%)$ & $0(0 \%)$ & $1(4 \%)$ & $0(0 \%)$ & $1(1 \%)$ \\
$>1$ & $2(8 \%)$ & $0(0 \%)$ & $2(8 \%)$ & $1(4 \%)$ & $5(5 \%)$ \\
Total & $25(100 \%)$ & $25(100 \%)$ & $25(100 \%)$ & $25(100 \%)$ & $100(100 \%)$
\end{tabular}

Table II. Median and standard deviation of the distance $(\mathrm{mm})$ between the file and the apical foramen (AF).

\begin{tabular}{ccc}
\hline Electronic apex locators & Median & Sd \\
\hline Pixi & -0.106 & 0.601 \\
Root ZX II & -0.166 & 0.293 \\
Propex II & 0.061 & 0.789 \\
Raypex 6 & -0.156 & 0.55 \\
\hline
\end{tabular}

* Negative signs indicate a more coronal position to the AF. Sd: Standard deviation.

\section{DISCUSSION}

The purpose of this study was to compare the accuracy of AF location by third generation (Propex Pixi, Root ZX II) and fourth generation (Propex II, Raypex 6) electronic devices using a methodology similar to that of D'Assunção et al. (2007), Altunbas, et al. (2017) and Oliveira et al.

One of the most-studied locators is the Root ZX. Duran-Sindreu et al. determined that no significant differences were observed in its accuracy ex vivo or in vivo, with excellent performance in both cases. Guise et al. (2010) in an ex vivo study, showed that the Root ZX II located the apical foramen more accurately than Apex Locator and Precision Apex Locator. It has also been shown that the Root ZX II is effective in avoiding overestimation of the working length (D'Assunção et al., 2007) and for locating root perforations (D'Assunção et al., 2014). The results of these works agree with the findings in our study, in which the Root ZX II proved to be the most accurate of the devices tested.
Akisue et al. (2014) compared the accuracy of different locators according to the size of the apical foramen, observing that the MiniApex, Root ZX II and Elements Apex Locator were accurate in determining WL in all foramen sizes investigated, whereas the accuracy of iPex and Propex II was reduced in cases of larger foramina. Uneven results were obtained with Root ZX and Raypex 5, with the file point passing the principal foramen in some cases (Wrbas et al., 2007); the study authors therefore recommended withdrawing the instruments by $0.5 \mathrm{~mm}$ to reduce over-instrumentation.

The effect of pre-flaring or widening prior to determination of the WL has been studied, for example in the study of Brito-Júnior et al. (2012), who assessed the performance of the Root $Z X$ and the Novapex. This study found greater accuracy in the electronic measurements taken by the devices, both of which presented acceptable results in the palatine canals of upper molars. Similar results were reported by Ibarrola et al. (1999), who suggests that pre-flaring of the canals gives the files more uniform access to the apical foramen, improving the accuracy of the Root ZX. In our study, pre-flaring was carried out with SX files, which may have improved the accuracy results of the devices tested.

Another factor which may affect the behaviour of electronic locators is the irrigation solution selected. It has been suggested that third and fourth generation EALs perform better in clinical practice when accompanied by a highly conductive solution, unlike second generation devices (Venturi \& Breschi, 2005; 
Carvalho et al., 2010). In our study, the use of $2.5 \%$ $\mathrm{NaOCl}$, a highly conductive irrigant, did not have a negative affect on the results obtained using third and fourth generation EALs, and even improved the performance of the devices in clinical practice. Furthermore, the accuracy of fourth generation devices (Propex II) was not affected by pulp vitality (Milanovic et al., 2015).

Oliveira et al. assessed various devices, as well as protocols for their use. This author found that EALs produce the best results when the electronic measurements are taken as far as but not beyond the $\mathrm{AF}$; for this case, there were no differences between the devices assessed (Root ZX II, Raypex 6, Apex ID, Propex II and Propex Pixi). These results are similar to those of the present study, in which there were no significant differences between the locators tested.

One limitation of this ex vivo study is that the results obtained cannot be extrapolated directly to clinical practice; however it offers the advantage of allowing all the samples to be standardised, for example the type of tooth used, work protocol, and chemicalmechanical preparation carried out by a single operator, thus ensuring a truer comparison between the devices. In 2012, Duran-Sindreu compared the readings obtained ex vivo and in vivo, finding no statistically significant differences; this enhances the validity of $e x$ vivo studies of this kind.

In conclusion, the results obtained suggest that there are no significant differences in the accuracy of Propex II, Raypex 6, Propex Pixi and Root ZX II; however Root ZX II and Raypex 6 present better overall performance.

BETANCOURT, P.; MATUS, D.; MUÑOZ, J.; NAVARRO, P. \& HERNÁNDEZ, S. Precisión de cuatro localizadores de ápice en la determinación de la longitud de trabajo. Int. J. Odontostomat., 13(3):287-291, 2019.

RESUMEN: El límite apical radicular para la instrumentación y obturación es un tema controversial, debido a la alta complejidad morfológica que presenta la zona apical de la raíz. El desarrollo de localizadores de ápice electrónicos (EALs) ha hecho la determinación de la longitud de trabajo (WL) más predecible y con resultados más precisos. Sin embargo, el mecanismo de interpretación de cada dispositivo puede afectar la determinación de las mediciones en diferentes condiciones clínicas. Cien premolares fueron utilizados para comparar la efectividad de Propex II, Raypex 6, Propex Pixi y Root ZX II en localizar el foramen apical
(AF). No se observaron diferencias estadísticamente significativas cuando se comparó la precisión de medición entre los diferentes grupos de EALs, sin embargo, Root ZX II y Raypex 6 mostraron un mejor desempeño global.

PALABRAS CLAVE: raíz dentaria, anatomía, endodoncia, localizador electrónico apical.

\section{REFERENCES}

Akisue, E.; Gratieri, S. D.; Barletta, F. B.; Caldeira, C. L.; GrazziotinSoares, R. \& Gavini, G. Not all electronic foramen locators are accurate in teeth with enlarged apical foramina: an in vitro comparison of 5 brands. J. Endod., 40(1):109-12, 2014.

Altunbas, D.; Kustarci, A.; Arslan, D. \& Er, K. In vitro comparison of four different electronic apex locators to determine the major foramen using the clearing technique. Niger. J. Clin. Pract., 17(6):706-10, 2014

Altunbas, D.; Kustarcı, A. \& Toyoglu, M. The influence of various irrigants on the accuracy of 2 electronic apex locators in locating simulated root perforations. J. Endod., 43(3):439-42, 2017.

American Association of Endodontists (AAE). Glossary of Endodontic Terms. $7^{\text {th }}$ ed. Chicago, American Association of Endodontists, 2003.

Brito-Júnior, M.; Camilo, C. C.; Moreira-Júnior, G.; Pecora, J. D. \& Sousa-Neto, M. D. Effect of pre-flaring and file size on the accuracy of two electronic apex locators. J. Appl. Oral Sci., 20(5):538-43, 2012.

Carvalho, A. L.; Moura-Netto, C.; Moura, A. A.; Marques, M. M. \& Davidowicz, H. Accuracy of three electronic apex locators in the presence of different irrigating solutions. Braz. Oral Res., 24(4):394-8, 2010.

Custer, L. E. Exact methods of locating the apical foramen. J. Nat. Dent. Assoc., 5(8):815-9, 1918.

D'Assunção, F. L.; de Albuquerque, D. S.; Salazar-Silva, J. R.; de Queiroz Ferreira, L. C. \& Bezerra, P. M. The accuracy of root canal measurements using the Mini Apex Locator and Root ZXII: an evaluation in vitro. Oral Surg. Oral Med. Oral Pathol. Oral Radiol. Endod., 104(3):e50-3, 2007.

D'Assunção, F. L.; Sousa, J. C.; Felinto, K. C.; de Medeiros, T. C.; Leite, D. T.; de Lucena, R. B. \& de Oliveira Lima, J. Accuracy and repeatability of 3 apex locators in locating root canal perforations: an ex vivo study. J. Endod., 40(8):1241-4, 2014.

de Vasconcelos, B. C.; Araújo, R. B. R.; Silva, F. C. F. A.; Luna-Cruz, S. M.; Duarte, M. A. H. \& Fernandes, C. A. O. In vivo accuracy of two electronic foramen locators based on different operation systems. Braz. Dent. J., 25(1):12-6, 2014.

Ding, J.; Gutmann, J. L.; Fan, B.; Lu, Y. \& Chen, H. Investigation of apex locators and related morphological factors. J. Endod., 36(8):1399-403, 2010.

Duran-Sindreu, F.; Stöber, E.; Mercadé, M.; Vera, J.; Garcia, M.; Bueno, R. \& Roig, M. Comparison of in vivo and in vitro readings when testing the accuracy of the Root ZX apex locator. J. Endod., 38(2):236-9, 2012.

Guise, G. M.; Goodell, G. G. \& Imamura, G. M. In vitro comparison of three electronic apex locators. J. Endod., 36(2):279-81, 2010.

Haffner, C.; Folwaczny, M.; Galler, K. \& Hickel, R. Accuracy of electronic apex locators in comparison to actual length--an in vivo study. J. Dent., 33(8):619-25, 2005.

Ibarrola, J. L.; Chapman, B. L.; Howard, J. H.; Knowles, K. I. \& Ludlow, M. O. Effect of preflaring on Root ZX apex locators. J. Endod., 25(9):625-6,1999. 
Lee, S. J.; Nam, K. C.; Kim, Y. J. \& Kim, D. W. Clinical accuracy of a new apex locator with an automatic compensation circuit. $J$. Endod., 28(10):706-9, 2002.

Marigo, L.; Gervasi, G. L.; Somma, F.; Squeo, G. \& Castagnola, R. Comparison of two electronic apex locators on human cadavers. Clin. Oral Investig., 20(7):1547-50, 2016.

Marroquín, B. B.; Fernández, C. C.; Schmidtmann, I.; Willershausen, B. \& Goldberg, F. Accuracy of electronic apex locators to detect root canal perforations with inserted metallic posts: an ex vivo study. Head Face Med., 10:57, 2014.

Martínez-Lozano, M. A.; Forner-Navarro, L.; Sánchez-Cortéz, J. L. \& Llena-Puy, C. Methodological considerations in the determination of working length. Int. Endod. J., 34(5):371-6, 2001.

Milanovic, I.; Ivanovic, V.; Vujaskovic, M.; Ignjatovic, S. \& Miletic, V. Accuracy of three electronic apex locators in determining the apical foramen in multi-rooted teeth: Randomised clinical and laboratory study. Aust. Endod. J., 41(1):35-43, 2015.

Oliveira, T. N.; Vivacqua-Gomes, N.; Bernardes, R. A.; Vivan, R. R.; Duarte, M. A. H. \& Vasconcelos, B. C. Determination of the accuracy of 5 electronic apex locators in the function of different employment protocols. J. Endod., 43(10):1663-7, 2017.

Somma, F.; Castagnola, R.; Lajolo, C.; Paternò Holtzman, L. \& Marigo, L. In vivo accuracy of three electronic root canal length measurement devices: Dentaport ZX, Raypex 5 and ProPex II. Int. Endod. J., 45(6):552-6, 2012.

Tampelini, F. G.; Coelho, M. S.; Rios, M. A.; Fontana, C. E.; Rocha, D. G. P.; Pinheiro, S. L. \& Bueno, C. E. D. S. In vivo assessment of accuracy of Propex II, Root ZX II, and radiographic measurements for location of the major foramen. Restor. Dent. Endod., 42(3):200-5, 2017.

Üstün, Y.; Aslan, T.; Sekerci, A. E. \& Sagsen, B. Evaluation of the reliability of cone-beam computed tomography scanning and electronic apex locator measurements in working length determination of teeth with large periapical lesions. J. Endod., 42(9):1334-7, 2016.

Venturi, M. \& Breschi, L. A comparison between two electronic apex locators: an in vivo investigation. Int. Endod. J., 38(1):36-45, 2005.

Wrbas, K. T.; Ziegler, A. A.; Altenburger, M. J. \& Schirrmeister, J. F. In vivo comparison of working length determination with two electronic apex locators. Int. Endod. J., 40(2):133-8, 2007.
Corresponding author:

Pablo Betancourt

Assistant Professor

Research Centre for Dental Sciences (CICO)

Endodontic Laboratory

Universidad de La Frontera

Avenida Francisco Salazar 01145

Temuco

CHILE

Email: pablo.betancourt@ufrontera.cl

Received: 13-12-2018

Accepted: 08-04-2019 